\title{
Flexural-slip folding and fold-accommodation faulting in the Tethyan Sedimentary Zone, NW Himalayas
}

\author{
Dilip K Mukhopadhyay \\ Department of Earth Sciences, Indian Institute of Technology Roorkee, Roorkee 247667, INDIA \\ E-mail:dilipfes@iitr.ernet.in
}

In the northwestern Himalayan orogenic segment, a highly metamorphosed and deformed lithotectectonic zone (Central Crystallines) separates two sedimentary belts. The southern sedimentary belt consists of largely upper Proterozoic Lesser Himalaya Zone (LHZ), and Tertiary Sub-Himalaya Zone (SHZ). In recent years, detailed structural studies including application of cross-section balancing techniques by many workers show that the LHZ and SHZ constitute a typical frontal fold-thrust belt. Thrust faulting and fault-related folding over a gentle northerlydipping detachment are the main structural elements in this belt.

The Tethyan Sedimentary Zone (TSZ) occurring north of the Central Crystallines, contains a continuous sequence of sedimentary rocks ranging in age from Proterozoic through Palaeozoic to Cretaceous. The basal part of TSZ contains very lowgrade metamorphic rocks at places. These rocks were deposited on the leading edge of the northerly moving Indian plate. The contact between the Central Crystallines and the TSZ is marked by a system of low northerly dipping normal faults collectively known as South Tibet Detachment System (STDS). The stratigraphy and paleontology of this zone have been studied for more than a hundred years and they are very well known. However, the deformation history in this belt is still not very well understood.

The TSZ in the Himachal Himalayas consists primarily of limestones with subordinate amount of sandstones and shales. The rocks are thinly bedded with thickness of individual beds ranging in scale from a few $\mathrm{mm}$ through few $\mathrm{cm}$ to tens of $\mathrm{cm}$. The wellbedded rocks trace spectacular folds in outcrop to intermediate scales. Folds, tens of meters in amplitude, are seen on subvertical valley surfaces cut at high angles to strike. Tightness of folds varies from very open to very tight. The folds have straighter limbs and sharp hinges of limited areal extent giving rise to chevron or kink fold geometry. Axial planes are usually steeply dipping to subvertical and hinges are horizontal or gently plunging. Thus the folds usually have horizontal upright geometry. Evidence of layer-parallel slip is very common with the slip direction towards the hinges of mesoscopic folds. The folds have developed through buckling of thinly-bedded multilayer with high viscosity contrast and moderate to low packing distance. The folding is not related to faulting. Consideration of map pattern, stratigraphic relations and analysis of structural data show that the large-scale structure can be best described as a horizontal upright synclinorioum. There are innumerable faults present in outcrop to intermediate scales. These faults are fold-accommodation faults and are accommodation structures developed during folding. Therefore faulting is a consequence of folding. This interpretation is in contrast to a few recent works that suggest the deformation pattern in the TSZ is somewhat akin to frontal fold-thrust belt seen in the Lesser and Sub-Himalaya zones. 